\title{
The Picture of Dorian Gray. The Return of the Real - A Lacanian Perspective -
}

\author{
Daniela Cârstea \\ University of Bucharest
}

\begin{abstract}
In a Lacanian plot of a story, a person experiences himself only inasmuch as he constructs an ideal image of his 'self' and seduces others into recognizing it. It would mean that man is in a continual chase for self-discovery, which is not, nevertheless, the case of Wilde's Dorian Gray, as he first appears in the studio of his friend, Basil Halward, for yet another session of his modelling for the painter's portrayal of him. The eccentric relationship, between what Dorian is and what he desires to be makes the reader aware of the lack-in-being that haunts the human subject. Even if the portrait fills his lack-in-being, by bestowing upon him everlasting beauty, it experiences a gap within itself likewise. It lacks life, if we were to apply to it what Lacan asserted about words: "as symbols for something that is absent, the words are a presence that, however concretely presented, implies a residue of unnameable absence beyond what can be consciously known". Yet it becomes more Dorian-like in proportion as Dorian himself gets alienated from his self, so that eventually it becomes the real Dorian. When the latter fully realizes that reality recedes from the further advancing one gained by the portrait, he tries to reconquer his life, even if the price is his death.
\end{abstract}

Keywords: dis-coincidental personalities; authenticating gaze; primary narcissism; secondary narcissism; ego ideal. 